\title{
Macquarie River floodplain flow modeling: implications for ecogeomorphology
}

\author{
S. G. Sandi Rojas, J. F. Rodríguez \& P. Saco \\ Civil and Environmental Engineering, University of Newcastle, Newcastle, NSW, Australia
}

G. Riccardi

Centre for Hydro-Environmental Research, University of Rosario, Santa Fe, Argentina

L. Wen \& N. Saintilan

Science Division, NSW Office of Environment and Heritage, Sydney, NSW, Australia

H. Stenta, F. Trivisonno \& P.A. Basile

Centre for Hydro-Environmental Research, University of Rosario, Santa Fe, Argentina

\begin{abstract}
This work presents preliminary results of implementing a quasi-2D hydrodynamic module (VMMHH 1.0) to simulate flows and flooding patterns throughout the Macquarie Marshes, south east Australia, in order to assess habitat requirements. The model uses an interconnected cell scheme that solves mass conservation and uses simplified versions of the momentum equations to represent flow between cells. This model has been used before to assess geomorphological changes in large river floodplains and vegetation evolution in estuarine wetlands, showing results consistent with cases of gradual floodplain inundation following overbank flow. The simplified characteristics of the quasi2D model allow for an adequate representation of hydrodynamic processes with similar performance of other higher dimensional models. Model results and computational times are compared with outputs from a conventional 1D/2D model (MIKE FLOOD) applied to the same domain showing that the VMMHH 1.0 is adequate for representation of floods in the Macquarie Marshes.
\end{abstract}

\section{INTRODUCTION}

The Macquarie Marshes are a complex system of interconnected marshes, swamps, lagoons and anabranching channels located on the lowland area of the Macquarie River, south-east Australia. This wetland is of great ecological importance and some areas have been recognized of international importance. They were declared Ramsar site in 1986 for meeting six out of nine Ramsar criteria (OEH 2012). The site offers a wide variety of flood-dependent plants and animals; including Red Gum forests and woodlands, grasslands, shrublands and sedgelands (Roberts \& Marston 2011, Rogers 2011); at least 52 species of waterbirds (Rogers et al. 2010); and many species of fish and frogs.

Over the last few decades, a significant reduction of habitat conditions and environmental assets of the Macquarie Marshes has been noted (Rogers et al. 2010). Water diversions and allocations translated into a decrease of flooding area and flooding frequency (Kingsford 2000), which in turn had a major impact on the flood-dependent vegetation. Between 1991 and 2008, northern areas of the wetlands have experienced terrestrial vegetation encroachment due to changes in inundation patterns (Thomas et al. 2010). This compromised the resilience of the wetland because it takes more time for this type of vegetation to retreat if flood regimes are reinstated.
Following the introduction of the Macquarie Marshes Adaptive Environment Management Plan (DECCW 2010) and the NSW River Restoration Program (DECCW 2011), a Decision Support System (DSS) was developed as a prototype in order to assist water management on the Macquarie Marshes. The DSS uses a Bayesian network of environmental response models, but flow simulation was accomplished by hydrodynamic modeling. A coupled 1D/2D MIKEFLOOD model was built for $1728 \mathrm{~km}^{2}$ of the Macquarie Marshes containing 36 key wetlands of the system (Wen et al. 2013). The model allows to investigate climate change and control structures impacts on the wetlands which leads to a better management and prioritization of water (Saintilan et al. 2013).

This paper shows preliminary results of a different approach to the Macquarie Marshes environmental management problems. The new approach takes into consideration the ecogeomorphological system i.e. an integration of geomorphology, hydrology and ecology (Saco \& Rodríguez 2013). Previous research has identified the different geomorphic environments present in the floodplain and main channel network of the Macquarie marshes, as well as channel breakdown mechanisms in a very dynamic area of the southern wetlands (Yonge \& Hesse 2009). Generally, meandering streams loose definition and become terminal wetlands only to regain channel form downstream. At a basin scale, reasons for channel breakdown have been attributed to decreas- 
ing discharges in the downstream direction and lack of basin confinement (Ralph \& Hesse 2010). At a local scale, vegetation plays a more important role in determining geomorphology. Dense reeds and aquatic grasses are often found in the floodplain channel networks of the Macquarie Marshes (Yonge \& Hesse 2009). Vegetation increases resistance to flow and so it affects flow regimes, especially during floods. In turn, reduction of flooding frequency dramatically affects flood dependent vegetation. It is seen that multiple ecological, hydrological and geomorphological feedbacks occur in the Macquarie Marshes, and therefore the proposal of an ecogeomorphologic approach.

The first phase for developing an ecogeomorphologic model consists of implementing a tool that allows continuous estimation of flooding patterns and flow regimes along the floodplain. Continuous simulation is required because ecogeomorphology feedbacks need to be studied in long term scenarios. The VMMHH 1.0 flow module was chosen as the tool for the flow simulation. This module combines a quasi-2D hydrodynamic model, CTSS8 (Riccardi 2000), and a data processing platform designed for use in Microsoft Windows, Simulaciones 2.0. The module is highly versatile and it has been used to model runoff in basins and floodplains (Garcia et al. 2007, Riccardi et al. 2010). It has also been modified to simulate erosion-deposition processes (Basile et al. 2010). Recently, the module has been used for modeling the ecogeomorphology of a coastal wetland in Newcastle, Australia (Trivissono et al. 2013). The previous examples show that one of the advantages of implementing this module is that the code can be modified to incorporate soil and vegetation processes.

Preliminary results presented here are compared to the previously implemented hydrodynamic model MIKE FLOOD (Wen et al. 2013). Same domain was simulated, same parameters were mostly used and similar flood events were chosen. Despite the fact that further calibration is necessary in order to achieve better predictions of flow before attempting to pair simulated flooding to ecological and geomorphological responses, the VMMHH 1.0 module can be implemented with similar performance levels to those obtained with the previously built model.

\section{SITE DESCRIPTION}

Figure 1 shows the simulated area of $1702.45 \mathrm{~km}^{2}$ and the complexity of the river network. In order to simplify the analysis, the domain was divided in 4 different sections. Zone 1 (Z1) is the southernmost part of the system containing two main channels, the Macquarie River (M. Ri.) and the Marebone Break (M. Br.). These streams are located in an agricultural zone, therefore they are channelized and they main- tain a well-defined cross section as they carry water north. Some parts of the reaches have levees on both side of the stream. Two discharge station gauges are found in the southern most boundary of the domain (No. 421088 and No. 421090), and the measured hydrographs are used as the upstream boundary conditions for the model.

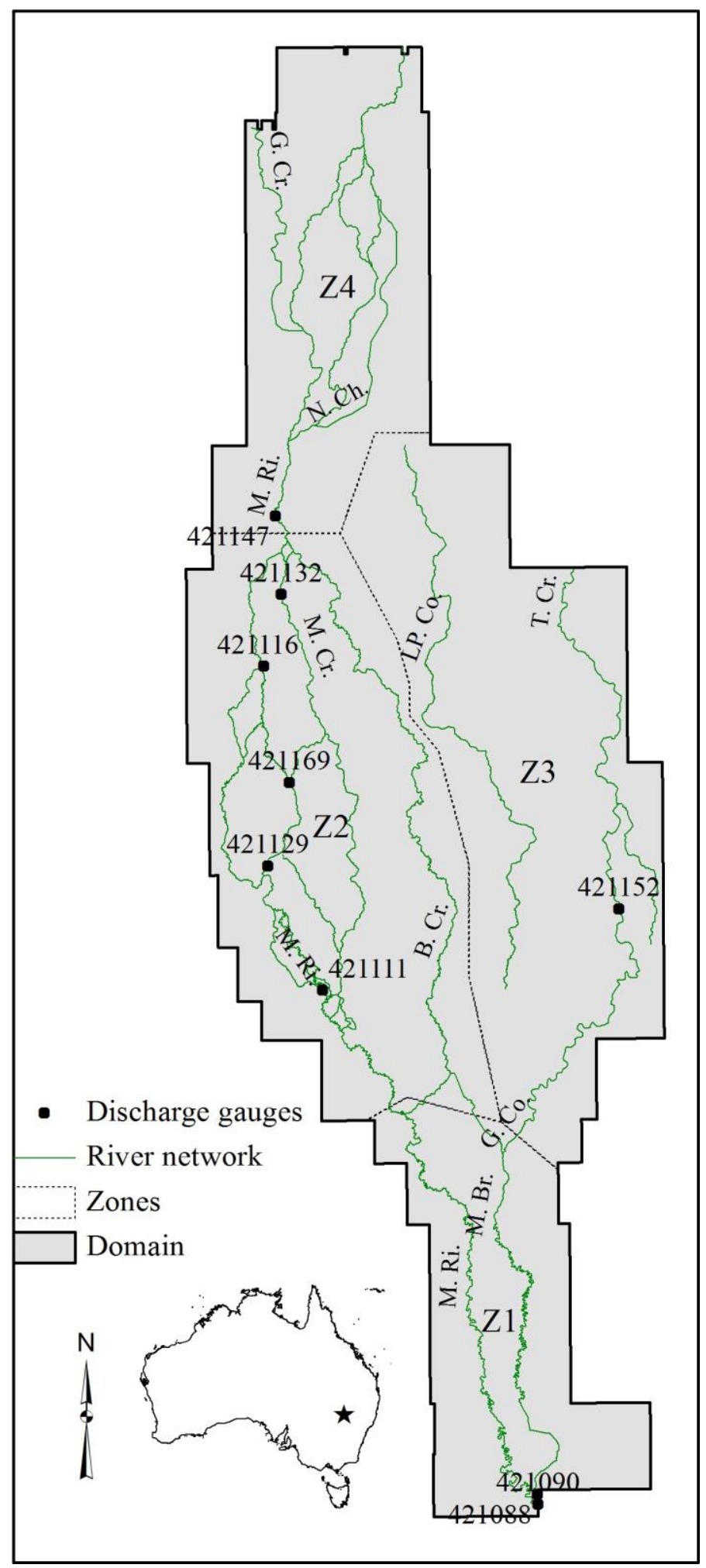

Figure 1. Simulated domain of the Macquarie Marshes. Flow of water follows South to North direction.

Exiting Z1 the streams split the flow into various channels. To the west side of the domain is Zone 2 
(Z2) where the Macquarie River, the Monkeygar Creek (M. Cr.) and the Bulgeraga Creek (B. Cr.) form a mesh of channels and reform into one single stream before entering the northern section. This zone contains the southern marshes which form a dynamic system of their own (Yonge \& Hesse 2009), and some areas defined as Ramsar sites. The streams in Z2 start as meandering rivers and then lose sinuosity where they meet with the marshes located in this area (Terminal Marsh, Monkey Marsh and the Buckiinguy Swamp). The channel cross sections along Bulgeraga Creek maintain their form, but other streams in $\mathrm{Z} 2$ are less defined and lose water to the floodplain. Later they regain channel shape and reconnect with other reaches. In Z2, water leaves the simulated domain in a few points of the floodplain. These volume losses are assumed minor and are not considered in the model. Five discharge station gauges are available for analyzing this area.

Zone $3(\mathrm{Z3})$ is located to the east. The Gum Cowal (G. Co.) drains water until it connects with the Terrigal Creek (T. Cr) and finally leaves the domain. Channel definition is not lost along the Gum Cowal or the Terrigal Creek, but in some reaches the active stream gets wider and shallower and the low flow channel is free to change within this width. Water coming in from the Terrigal Creek is unmeasured and unaccounted for in the model. The Long Plain Cowal (LP. Co.) is a stream disconnected from the rest of the network and only receives water from the floodplain; it carries water north until the channel becomes practically unnoticeable. Only one of the selected discharge gauges is found in this zone (No. 421152).

The northernmost area of the domain, Zone 4 (Z4), contains the perennial northern marshes and the other areas declared as Ramsar sites. The Ginghet Creek (G. Cr.) derives from the Macquarie River and drains water to the west border of the domain. A controlled man-made channel (N. Ch.) surrounds the northern marshes on the east side and carries water north until it reconnects to the Macquarie River. Finally, the Macquarie River runs across the floodplain where channels lose definition. The only discharge measurement in Z4 is at the entrance (No. 421147), but during high flows considerable volumes of water enter and leave the area throughout the floodplain.

\section{METHODS}

\subsection{Description of the model}

The VMMHH 1.0 module is based on a spatially distributed cell scheme and solves multidirectional hydrologic and hydraulic relations between cells. Active cells are called elements and they can be river type or valley type. River elements have the same size as valley elements, but contain a channel in the centre, capturing both characteristics of the floodplain and the stream. Processing the input data is done with the SIMULACIONES 2.0. Source data such as topography, element characteristics, input discharges, rainfall and boundary conditions; is organized and used as an input for the quasi-2D model, CTSS8.

Governing equations are established by two fundamental hypotheses. First, the stored volume in each element is a function of the water depth; therefore the continuity equation in each cell may be expressed as a balance of the rate of change in volume and the sum of the discharges entering and exiting the cell such as rainfall, evapotranspiration, infiltration and discharges from adjacent elements.

The second hypothesis is that the discharges between cells in a given time depend on the approximations taken for solving Saint Venant's momentum equation. According to the element link (river-river, valley-valley or river-valley), the momentum equation may be solved as a kinematic wave, a diffusive wave, a quasi-dynamic wave or a dynamic wave. The module uses the Gauss-Seidel method to solve the differential equations and stability of the model is assured with Courant-Friedrichs-Lewy condition. A full description of the CTSS8 formulation may be found in Riccardi (2000).

\subsection{Domain and river network}

The simulated area was discretized using a rectangular $90 \times 90 \mathrm{~m}$ grid, similarly to Wen et al. (2013). The grid was obtained from resampling of a $1 \mathrm{~m}$ resolution LiDAR Digital Elevation Model (DEM). The model has a total of 210,179.00 elements. The size of the grid was a compromise between computational times and level of detail required to describe the flow dynamics. Elements representing the floodplain were assigned a Manning's coefficient value obtained from the roughness map developed in Wen et al. (2013). The Manning's coefficients assigned are based on soil and vegetation characteristics and range from 0.02 to 0.08 .

The river network is represented by a 6739 elements. Stream cross sections in the model are simplified as trapezoidal areas, so parameters were assigned to different river reaches based on cross sections obtained from the $1 \mathrm{~m}$ DEM. There is an error involved for highly meandering rivers because the $90 \mathrm{~m}$ grid cannot represent all the curves of the stream, so special attention was paid to these areas to get the best representation of the river network. In order to eliminate resampling errors and to ensure a uniform channel bottom slope of the different streams, element elevations had to be manually changed for all the river elements. Manning's coefficient implemented for the river network was part of the calibration. Constant values of roughness coefficients were assigned to different reaches ranging 
from 0.05 to 0.07 . In reality some of the flow paths have no channel due to complete channel breakdown, but in order to ensure continuity of the model, they were simulated as river elements with roughness values of 0.1 . This produced a similar behavior to the floodplain's valley elements.

\subsection{Control structures and earthworks}

Earthworks have an attenuating effect because they impede overbank flows in some areas of the Macquarie Marshes (Steinfeld \& Kingsford 2013). Control structures and earthworks also redirect water for agricultural use so that the terminal marshes receive less water. Details of earthworks were not available, but details of 24 control structures were incorporate in the VMMHH 1.0. The number of control structures introduced in the VMMHH 1.0 is less than the amount of control structures incorporated by Wen et al. (2013). This fact will be taken into consideration for comparison of results.

\subsection{Simulated Events and Boundary Conditions}

Three types of boundary condition can be incorporated into the model as a relation of the link between elements. Upstream boundary conditions may be a hydrograph input and the downstream boundary condition may either be a rating table of discharge versus water depth or a table of water depths distributed in time. Upstream boundary conditions were set as gauged hydrographs located in the Macquarie River and the Marebone Break (gauges No. 421090 and No. 421080 respectively). Downstream boundary conditions were assigned as discharge versus height tables. Three downstream boundary conditions were placed in the channel network: Terrigal Creek in the East (Z3), Ginghet Creek in the West (Z4), and the Macquarie River at the northern part of the domain (Z4). Seven more downstream boundary conditions were placed in the floodplain. All other boundary conditions were set as no-flow.

Inundation maps based on remote sensing satellite images developed by NSW Office of Environment and Heritage were available to calibrate the model. For each condition, i.e. low, medium and high flow, one event was chosen to be compared with results obtained by Wen et al. (2013). Calculations were carried out until the peak flow occurred to best represent the inundation map. The period for low flow event extended from September 1997 to February 1998 and presented a peak flow on the 25 of October 1997. The period for the medium flow event extended from July to November 1993 and presented a peak flow on the 16 of October 1993. The selected high flow event lasted from May to December 1990 and presented a peak flow on the 15 of August 1990. Initial conditions for the three events were set as no water in the floodplain or channels after doing a few runs and checking that it has no major implication in the results.

Water originating from rainfall was not introduced in the model because flooding is mostly produced by input discharges. An important difference between the MIKE FLOOD and the VMMHH 1.0 is that the later did not include infiltration like the MIKE 21 HD - Infiltration and Leakage Module. Transmission losses have been found to be significant in arid environments, thus overestimation is expected especially for low flow events since they present higher leakage rates than medium flow and high flow events (Wen et al. 2013).

\subsection{Model comparison}

In order to make a comparison between VMMHH 1.0 and the MIKE FLOOD, a statistical evaluation was conducted. Pearson's correlation coefficient (R), Nash-Sutcliffe efficiency (NSE) and the percent BIAS (PBIAS) were calculated for the seven selected gauges. Rule for evaluating performance is presented in Table 1.

Table 1. Evaluation rule for performance indicators.

\begin{tabular}{llll}
\hline Condition & \multicolumn{2}{l}{ Range of values } & \\
\cline { 2 - 3 } & $\mathrm{R}$ & $\mathrm{NSE}$ & PBIAS* \\
\hline Very good & $\geq 0.85$ & $\geq 0.75$ & \pm 10 \\
Good & $0.84-0.65$ & $0.74-0.65$ & $\pm 10- \pm 15$ \\
Satisfactory & $0.64-0.50$ & $0.64-0.50$ & $\pm 15- \pm 25$ \\
Poor 0.86 & $<0.50$ & $<0.50$ & $> \pm 25$
\end{tabular}

* A negative PBIAS means overestimation and positive PBIAS means underestimation.

Comparison of inundation maps generated from both models was not possible because the maps obtained from the MIKE FLOOD were not available, but results obtained from the VMMHH 1.0 were visually compared to remote sensing inundation maps.

\section{RESULTS AND DISCUSSION}

Preliminary results obtained for this paper show a reasonable comparison to previously obtained results by Wen et al. (2013). Simulations times proved to be very similar between models. Magnitude of the flood affected the simulation time. For the low flow calculating times were between of 8 to 10 hours for 40 days of flooding. The medium flow event presented calculation times between 10 and 18 hours and simulation of the high flow event lasted 15 to 20 hours for 40 days of flooding.

\subsection{Low flow event}

Performance indicators for the low flow event are presented in Table 2. Pearson coefficient shows a 
good performance in most cases and very good for gauging stations No. 421116 and No. 421169. The NSE is evaluated as poor for all stations and PBIAS also indicates a poor performance except for station No. 421152.

Table 2. Performance indicators for low flow events.

\begin{tabular}{|c|c|c|c|c|c|c|}
\hline \multirow[t]{2}{*}{ Gauge } & \multicolumn{3}{|c|}{ VMМHН 1.0.} & \multicolumn{3}{|c|}{ MIKE FLOOD } \\
\hline & $\mathrm{R}$ & NSE & PBIAS & $\mathrm{R}$ & NSE & PBIAS \\
\hline 421147 & 0.71 & -4.45 & -77.16 & 0.97 & 0.59 & -47.80 \\
\hline 421132 & 0.77 & -2.32 & -61.86 & & & \\
\hline 421116 & 0.88 & -0.57 & -135.17 & 0.97 & 0.91 & 1.37 \\
\hline 421169 & 0.86 & 0.32 & -89.46 & 0.99 & 0.92 & 5.92 \\
\hline 421129 & 0.78 & -19.37 & -765.85 & 0.99 & 0.91 & 7.36 \\
\hline 421111 & 0.82 & -2.11 & -32.93 & 0.97 & 0.38 & 51.74 \\
\hline 421152 & 0.66 & 0.31 & 13.65 & & & \\
\hline
\end{tabular}

The results contrast with the ones obtained by Wen et al. (2013) where the best simulation performance was for low flow events and underestimation was noticed for some gauging stations. In the case of the VMMHH 1.0, overestimation was expected because the module did not include an infiltration method for losses. This is resembled upon the negative PBIAS values with poor performance in most stations. Figure 2 shows the plot of measured against simulated data for station gauge No. 421129, which presented the poorest performance according to PBIAS. Despite the fact that overestimation is evident, the general tendency of the data seems to be maintained for the simulation period, explaining a good Pearson's coefficient. The other stations with a negative PBIAS show similar situation but the overestimation is less pronounced. In contrast, Figure 3 shows the measured and simulated results for station gauge No. 421152 with a good positive PBIAS, a good Pearson's correlation and a positive poor NSE. Results for this station are considered a good estimation and do not systematically overpredict, but that may be due to flow compensation from control structures as discussed in Section 4.1.1 for the medium flow event.

A visual inspection of Figure $4 a, b$ shows that no mayor differences are found in inundation extents of $\mathrm{Z1}, \mathrm{Z} 2$ and Z3. For Z4, the VMMHH 1.0 presented problems in simulating the northern marsh. Virtually no flooding occurs in the perennial northern wetland even when simulated discharge entering $\mathrm{Z4}$ is overestimated (gauge No. 421147). Inundation maps shown in Figure $4 \mathrm{~b}$, d, f represent water depths above $5 \mathrm{~cm}$ in order to not include some numerical noise. Generating inundations maps with a minimal water depth of $1 \mathrm{~mm}$ shows parts of the northern marsh inundated; therefore the model is simulating flooding but heights are not representative. Surface elevations in this zone were reduced by Wen et al. (2013) in order to account for high dense vegetation that may have caused a problem with the LiDAR data. In the case of the VMMHH 1.0, decreasing the floodplain elevation proved to have little effect. The problem may be due to a high hydraulic conductivity of the fictitious channels introduced in the northern marsh, so modification of the channel parameters will be carried out in future works.

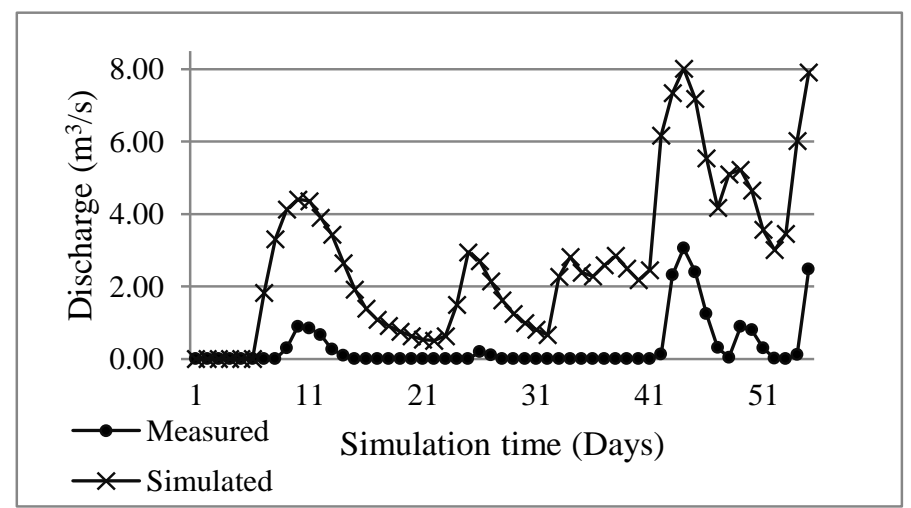

Figure 2. Registered and simulated discharges for low flow event in gauge station No. 421129.

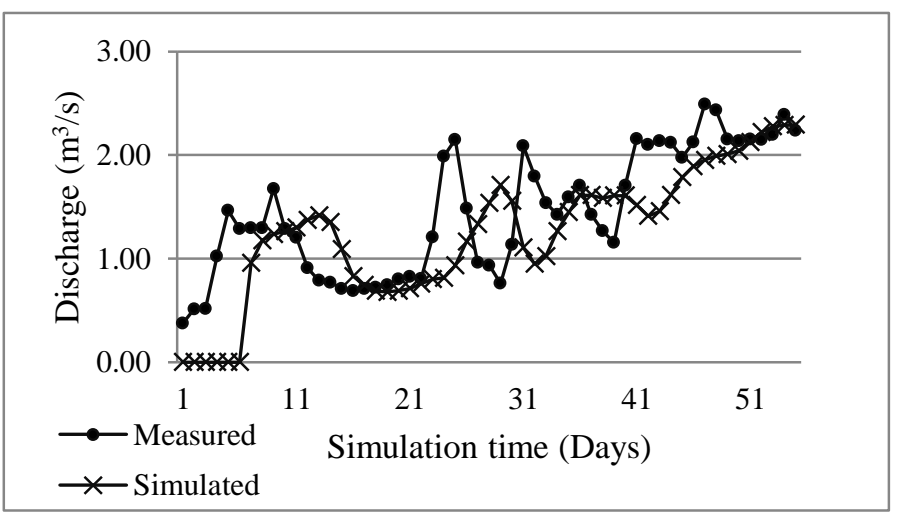

Figure 3. Measured and simulated discharges for low flow event in gauge station No. 421152.

\subsubsection{Medium flow event}

Performance indicators showed better simulation results for the medium flow event than the low flow event. Evaluation of Table 3 shows that performances of both models are similar for the medium flow event. Overestimation is still present for five of the discharge station gauges, but a good performance was observed for the most part. Results plotted in Figure 5 are for station gauge No.421147, were the VMMHH 1.0 had the best performance. 

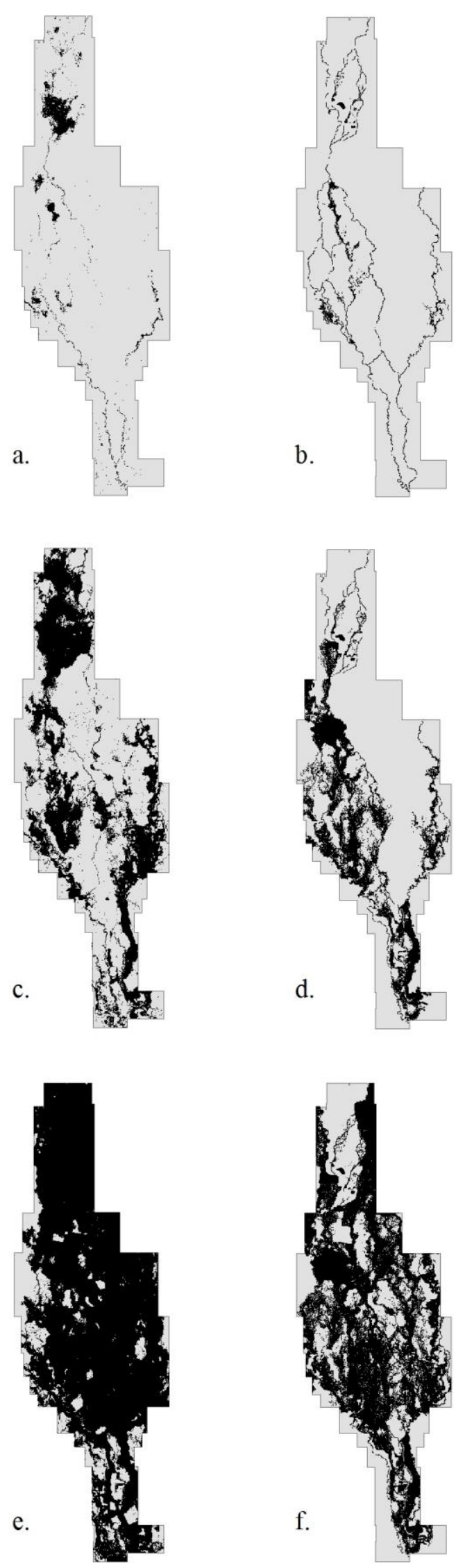

Figure 4. Inundation maps of the selected events. Remote sensing maps a, c and e for low, medium and high flow events respectively. Modeled event maps $\mathrm{b}, \mathrm{d}$ and $\mathrm{f}$ for low, medium and high flow respectively.
Table 3. Performance indicators for medium flow events.

\begin{tabular}{llllllll}
\hline Gauge & \multicolumn{3}{l}{ VMMHH 1.0. } & & \multicolumn{3}{l}{ MIKE FLOOD } \\
\cline { 2 - 3 } \cline { 6 - 8 } & R & NSE & PBIAS & R & NSE & PBIAS \\
\hline 421147 & 0.94 & 0.82 & -4.78 & & 0.90 & 0.19 & 5.82 \\
421132 & 0.85 & 0.21 & 26.11 & & 0.90 & 0.37 & -5.19 \\
421116 & 0.83 & -1.54 & -50.68 & & 0.93 & 0.59 & -14.00 \\
421169 & 0.65 & 0.42 & -0.79 & & 0.91 & -100.5 & 27.93 \\
421129 & 0.93 & 0.75 & -8.08 & 0.95 & -31.48 & -52.82 \\
421111 & 0.76 & -16.88 & -114.27 & 0.80 & 0.08 & -1.51 \\
421152 & 0.67 & 0.20 & 45.87 & 0.88 & 0.27 & 1.37 \\
\hline
\end{tabular}

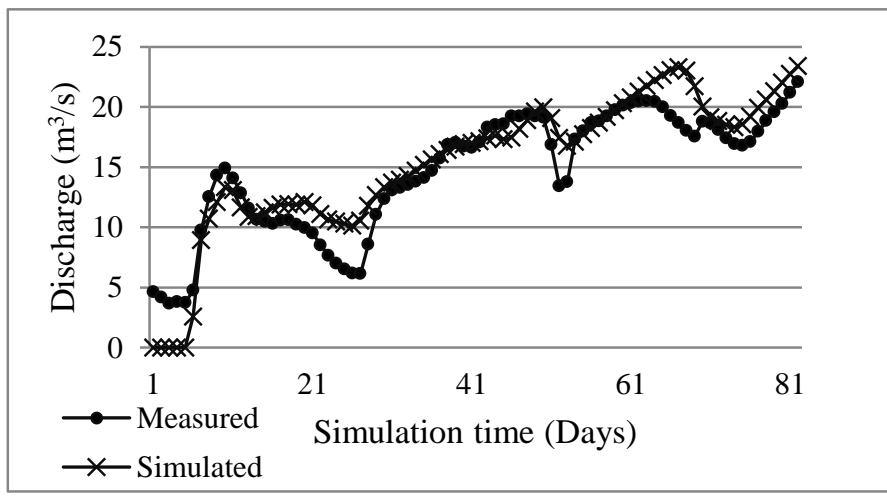

Figure 5. Measured and simulated discharges for medium flow event in gauge station No. 421147.

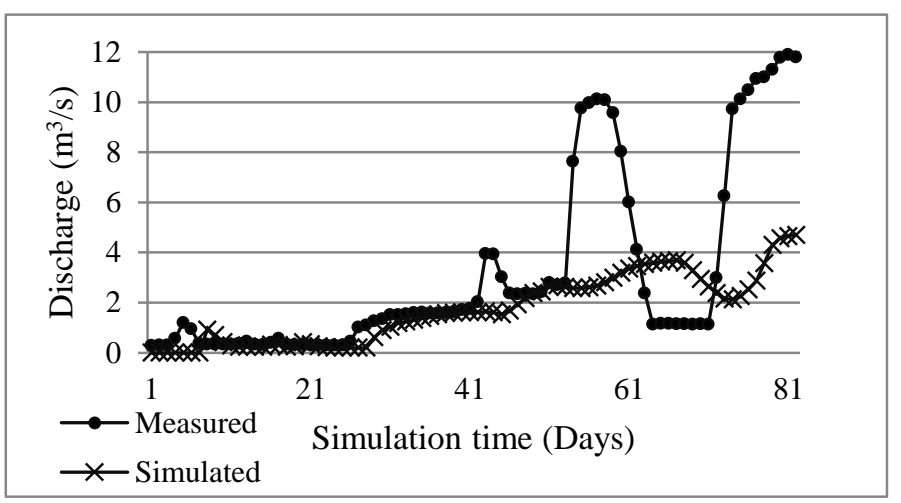

Figure 6. Measured and simulated discharges for medium flow event in gauge station No. 421152.

Inundation extents in Figures $4 \mathrm{c}, \mathrm{d}$ are similar in $\mathrm{Z} 1$ and $\mathrm{Z} 2$, but underestimation in $\mathrm{Z} 3$ was noticed as reflected by PBIAS values of station gauge No. 421152. Pearson's correlation was only satisfactory for this station; therefore simulated discharges entering $\mathrm{Z} 3$ were not enough and did not follow the registered pattern. Figure 6 shows that simulated discharges are majorly attenuated during peak flows. This may be due to the fact that less control structures were introduced for the VMMHH 1.0. It was noticed that some gates and culverts are located at the bifurcation of the Gum Cowal and the Marebone Break. Functioning of these structures has a clear effect on the redistribution of water entering the Gum Cowal, but details for incorporating them in the model were not available. In contrast, the results obtained by Wen et al. (2013) using the control struc- 
tures show small underestimation of discharges in station No. 421152 and a good Pearson's correlation.

Flooding in Z4 presented the same problem as low flow events, resulting in insufficient water flooding the northern plain. The problem does not seem to be caused by lack of water since the simulated discharges entering the northern marshes show little overestimation and a very good performance at the gauge station No. 421147 (Fig. 5). Performance indicators for this station were better than the results obtained with the MIKE FLOOD for medium flow events. This supports the idea that the definition of the river network in the northern marsh is not adequate so a redefinition of channel parameters and boundary conditions must be sought in future works.

\subsection{High flow event}

The Pearson's coefficients obtained for the high flow event show good and very good performance (Table 4). Overall the Pearson correlation was higher than the results obtained by Wen et al. (2013), with similar NSE and PBIAS. Results were mostly underestimated as expected because additional inputs of discharge into the domain were not considered. This is especially important because the high flow event simulated is one of the largest in the last few decades (Ralph \& Hesse 2010). This reflects directly on the inundation extent. From Figure $4 \mathrm{e}$, f it can be seen that flooding is underestimated in all 4 zones. In Z1, over-flows from the Macquarie River seem to follow a different path than the ones observed form the remote sensing maps. In Z2 and Z3, the distribution of flooding is similar to the ones observed, but underestimation is present. Results for Zone 4 present the same problem in the distribution of floods along the northern marsh as with the other discharges.

Table 4. Performance indicators for high flow events.

\begin{tabular}{|c|c|c|c|c|c|c|}
\hline \multirow[t]{2}{*}{ Gauge } & \multicolumn{3}{|c|}{ VMМНH 1.0.} & \multicolumn{3}{|c|}{ MIKE FLOOD } \\
\hline & $\mathrm{R}$ & NSE & PBIAS & $\mathrm{R}$ & NSE & PBIAS \\
\hline 421147 & 0.79 & 0.57 & 11.65 & 0.71 & 0.11 & 1.40 \\
\hline 421132 & & & & 0.88 & -3.70 & 10.46 \\
\hline 421116 & 0.76 & 0.26 & -15.10 & 0.59 & -21.83 & -43.07 \\
\hline 421169 & 0.87 & -0.53 & 34.07 & 0.75 & -22.56 & 23.66 \\
\hline 421129 & 0.95 & 0.90 & 0.65 & 0.88 & -7.08 & -28.57 \\
\hline 421111 & 0.98 & -17.13 & -114.95 & 0.84 & -46.36 & 39.80 \\
\hline 421152 & 0.69 & -0.43 & 35.95 & 0.74 & 0.28 & -2.86 \\
\hline
\end{tabular}

A possible solution for simulating discharges that are not accounted for was proposed by Wen et al. (2013). Introduction of fictional discharges entering the domain from Terrigal Creek in Z3 would increase discharges from this area; however, this solution may only work for medium and high flows where underestimation is present.

\section{CONCLUSIONS}

The ecological deterioration of the Macquarie Marshes has led to extensive research involving various fields including geomorphology, ecology, flooding patterns and climate change. The present research attempts to integrate concepts and results from all these fields by introducing an ecogeomorphologic analysis. The first step in accomplishing this is to successfully recreate continuous floods along the wetlands by implementing a quasi-2D hydrodynamic module (VMMHH 1.0). One of the advantages of implementing this module is its versatility to incorporate the analysis of different assets to its code.

Results obtained from a preliminary calibration of the module were compared to results obtained from a coupled 1D/2D hydrodynamic model. Both models seem to have similar computational times. Analysis of preliminary results showed that the module is appropriate for the Macquarie Marshes and future enhancements were pointed out in order to achieve a better calibration.

Preliminary results revealed good and very good performance of the model for medium and high flow events, but underestimation and overestimation of discharges and flood extent are present. Underestimation of the flooding extent was particularly important for the high flow event because not all water entering the domain is accounted for. The introduction of fictitious hydrograph located in Terrigal Creek may help to improve underestimation.

Low flow events are overestimated with the VMMHH 1.0 thus the need to incorporate transmission and infiltration losses in future works.

For all three events, a problem simulating the northern marshes was noticed and further work must consider another revision of the river network in the northern marshes and the downstream boundary conditions.

\section{IMPLICATIONS FOR ECOGEOMORPHOLOGICAL MODELING AND FUTURE WORK}

Further calibration of the model will allow for continuous simulation of flows in the Macquarie Marshes and calculation of inundation frequencies, flooding periods and inundation depths. This data will determine vegetation establishment according to preference values for the different vegetation species. Current model results underpredict inundation extent in the northern marshes, which will impact on the capabilities of this area to sustain the existing vegetation. Note that this is one the areas where the LiDAR data is less reliable, as it was of the few locations that had dense vegetation during the acquisition campaign. 
A sediment transport model will also be incorporated in order to identify areas of erosion and deposition. Depositional areas in this system can be readily identified by looking at channel density and channel breakdown zones (mainly Z2 and Z4). In these areas, sediment interacts with vegetation to generate channel breakdown and avulsion conditions that can dramatically change inundation patterns.

Vegetation and morphological changes will then be reintroduced into the hydrodynamic model to recalculate flooding regimes, thus feedbacks between flow, vegetation and geomorphology will be obtained. Once this module is developed, it can be used as a tool for long-term management of the wetland, predicting climate change impacts and evaluation of habitat requirements.

\section{REFERENCES}

BASILE, P. A., RICCARDI, G. A., ZIMMERMANN, E. D. \& STENTA, H. R. (2010) Simulation of erosion-deposition processes at basin scale by a physically-based mathematical model. International Journal of Sediment Research, 25, 91109.

DECCW (2010) Macquarie Marshes Adaptive Environmental Management Plan: Synthesis of information projects and actions. Sydney, NSW Department of Environment, Climate Change and Water.

DECCW (2011) NSW River Environmental Restoration Program: Final Report. Sydney, NSW Department of Environment, Climate Change and Water.

GARCIA, M., BASILE, P. A., RICCARDI, G. A. \& STENTA, H. (2007) Modelación Hidrodinámica de Sistemas CaucePlanicie de Inundación en Grandes Ríos Aluviales de Llanura. III Simposio Regional sobre Hidraulica de Rios. Cordoba, Argentina.

KINGSFORD, R. T. (2000) Ecological impacts of dams, water diversions and river management on floodplain wetlands in Australia. Austral Ecology, 25, 109-127.

OEH (2012) Macquarie Marshes Ramsar site: Ecological character description Macquarie Marshes Nature Reserve and U-block components. Sydney, NSW Department of Premier and Cabine.

RALPH, T. J. \& HESSE, P. P. (2010) Downstream hydrogeomorphic changes along the Macquarie River, southeastern Australia, leading to channel breakdown and floodplain wetlands. Geomorphology, 118, 48-64.

RICCARDI, G. (2000) A cell model for hydrological-hydraulic modeling. Journal of Environmental Hydrology, 8.

RICCARDI, G., ZIMMERMANN, E., BASILE, P., STENTA, H., SCUDERI, C., POSTIGLIONE, R., LOPEZ, C., ODICINI, L., GONZALEZ, A., MENDEZ, S. \& CIABBATTARI, L. (2010) Crecidas de diseño en cuencas de la región del Gran Rosario. IN UBALDO, C. \& MALINOW, G. (Eds.) Criterios para la determinacion de crecidad de diseño en sistemas cambiantes. Santa Fe, Argentina, Universidad Nacional del Litoral.

ROBERTS, J. \& MARSTON, F. (2011) Water regime for wetland and floodplain plants: a source book for the MurrayDarling Basin, Canberra, National Water Commission.

ROGERS, K. (2011) Vegetation. IN ROGERS, K. R., T. (Ed.) Flodplain wetland biota in the Murray-Darling basin: Water and Habitat Requirements. Australia.

ROGERS, K., RALPH, T. \& IMGRABEN, S. (2010) Water requirements of biota, geomorphology and climate change in the Macquarie Marshes. IN SAINTILAN, N. \& OVERTON, I. (Eds.) Ecosystem Response Modelling in the Murray-Darling Basin. CSIRO Publishing, Melbourne.

SACO, P. M. \& RODRÍGUEZ, J. F. (2013) 2.14 Modeling Ecogeomorphic Systems. IN SHRODER, J. F. (Ed.) Treatise on Geomorphology. San Diego, Academic Press.

SAINTILAN, N., ROGERS, K. \& RALPH, T. (2013) Matching research and policy tools to scales of climate-change adaptation in the Murray-Darling, a large Australian river basin: a review. Hydrobiologia, 708, 97-109.

STEINFELD, C. M. M. \& KINGSFORD, R. T. (2013) Disconnecting the Floodplain: Earthworks and their ecological effect on a dryland floodplain in the Murray-Darling basin, Australia. River Research and Applications, 29, 206-218.

THOMAS, R., BOWEN, S., SIMPSON, S., COX, S., SIMS, N., HUNTER, S., LU, Y., SAINTILAN, N. \& OVERTON, I. (2010) Inundation response of vegetation communities of the Macquarie Marshes in semi-arid Australia. IN SAINTILAN, N. \& OVERTON, I. (Eds.) Ecosystem response modelling in the Murray-Darling Basin. Melbourne, CSIRO Publishing.

TRIVISSONO, F., RODRIGUEZ, J. F., RICCARDI, G. \& SACO, P. (2013) Modelling Soil, Carbon and Vegetation Dynamics in Estuarine Wetlands Experiencing Sea-Level Rise. IAHR World Congress. China.

WEN, L., MACDONALD, R., MORRISON, T., HAMEED, T., SAINTILAN, N. \& LING, J. (2013) From hydrodynamic to hydrological modelling: Investigating long-term hydrological regimes of key wetlands in the Macquarie Marshes, a semi-arid lowland floodplain in Australia. Journal of Hydrology, 500, 45-61.

YONGE, D. \& HESSE, P. P. (2009) Geomorphic environments, drainage breakdown, and channel and floodplain evolution on the lower Macquarie River, central-western New South Wales. Australian Journal of Earth Sciences, 56, S35-S53. 